\title{
Study of Laboratory and Field Tests Related to Soil Compaction Based on Proficiency Testing Schemes
}

\author{
José Neves $^{1}$, Ana Duarte ${ }^{2}$ and Claúdia Silva ${ }^{2}$ \\ 1. Department of Civil Engineering, Architecture and Georesources, Instituto Superior Técnico, Universidade de Lisboa, Lisboa \\ 1049-001, Portugal \\ 2. RELACRE, Portuguese Association of Accredited Laboratories, Lisboa 1050-113, Portugal
}

Received: December 02, 2013 / Accepted: December 22, 2013 / Published: December 25, 2013.

\begin{abstract}
The main objective of the paper is to present some understandings of laboratory and field tests related to soil compaction and useful for quality control purposes. The methodology of this study is different of other similar works because it is based on proficiency testing schemes (PTS), involving several operators and test devices. The study was performed in the following test methods: laboratory Proctor compaction test; determination of density and unit weight of soil in place by the sand-cone method; and determination of density and water content of soil and soil-aggregate by nuclear methods. The paper describes the procedures followed for the PTS implementation. The statistical analysis is presented, firstly focusing on the repeatability and reproducibility of the test results. Secondly, beyond this analysis, the paper describes some studies related to practical aspects of the test methods: the influence of the manual or mechanical compaction devices in the modified Proctor test results; the comparison between direct transmission and the backscatter modes in the case of the wet density measurements obtained by the in situ nuclear method; the relationship concerning test results obtained by the nuclear and conventional methods used in the field quality control.
\end{abstract}

Key words: Proficiency testing schemes, soil compaction, density, water content, quality control.

\section{Nomenclature}

$C V_{r}: \quad$ Coefficient of variation of repeatability

$C V_{R}$ : Coefficient of variation of reproducibility

$r: \quad$ Repeatability limit

$R: \quad$ Reproducibility limit

$S D: \quad$ Standard deviation

$S D_{X}: \quad$ Standard deviation of the mean values

$S D_{r}: \quad$ Standard deviation of the repeatability

$S D_{R}: \quad$ Standard deviation of the reproducibility

$X$ : $\quad$ Average

$X_{X}$ : $\quad$ Average of the mean values

\section{Introduction}

Compaction is the natural procedure to promote the soil particles densification by the use of a mechanical energy and based on removing the air from its voids. The compaction technique is very important in the

Corresponding author: José Neves, Ph.D., professor, researchfields: civil engineering, geotechnics and transport in frastructures. E-mail: jose.manuel.neves@tecnico.ulisboa.pt. phase of earthworks for building, hydraulic and transportation infrastructures, because it is recognized as one of the most efficient and practical soil improvement technologies in the construction of any civil engineering project. Density and water content are the common parameters used in the quality control of soil compaction throughout the construction process. This information is essential for the design specifications given in terms of a minimum density and a specified range of water content.

Various methods currently exist for compaction monitoring purposes [1-3]. The nuclear method is the most commonly employed to determine soil density and water content because of its portability, simplicity of operation and reliability of results [1, 4]. Modern nuclear gauge offers two test modes for measuring the density namely direct transmission and backscatter. Despite the nuclear method advantages, it should be 
correlated with other techniques, conventional methods, such as sand cone testing. Nevertheless, these conventional methods are laborious and require the determination of the water content using the oven dry in laboratory or other equivalent test $[5,6]$.

The main purpose of this paper is to present some studies carried out in order to analyse: (1) the influence of manual or mechanical compaction devices in the modified Proctor test results; (2) the comparison between direct transmission and backscatter modes in the case of the wet density measurements obtained by the in situ nuclear method; (3) the relationship concerning test results obtained by nuclear (nuclear gauge) and conventional(sand cone replacement and drying oven) methods used in the field quality control.In comparison with other similar studies found in the literature $[5,6]$, the most important relevancy of this paper is the fact that these studies were based on proficiency testing schemes (PTS).

In general, the main objective of a PTS is to highlight the laboratory competence by evaluating its performance. Besides the description of PTS methodologies and laboratories' proficiency for the case of laboratory and fieldtests related to soil compaction, this paper also demonstrates how PTS could be a useful tool in order to achieve other concerns related to the tests [7].

The PTS were organized by the Portuguese Association of Accredited Laboratories (RELACRE) and have followed the requirements from ISO/IEC 17043 [8]. Participants were accredited laboratories according to EN ISO/IEC17025 [9] and an identification code number was attributed to each participant in order to guarantee the information confidentiality (e.g., L1).

Statistical analysis of the PTS's results was based on ISO5725 [10] and ISO13528 [11], comprising the following parameters: average and standard deviation; standard deviation of the repeatability and of the reproducibility; coefficients of variation of repeatability and of reproducibility; and repeatability and reproducibility limits. Cochran's and Grubbs's tests were used to detect and to remove outlier data.

\section{Materials and Methods}

\subsection{Laboratory Tests}

The laboratory tests related to the soil compaction characteristics were the modified Proctor tests performed in accordance with the standard ASTMD1557 [12]. The tests were undertaken by compacting the soil at a selected molding water in the cylindrical mold (101.6 mm diameter) in five layers and by applying a constant compaction effort given by twenty five impact blows per layer of a standard rammer manually operated (manual compaction) or an equivalent mechanical device (mechanical compaction). In both compaction methods, the characteristics of the rammer should correspond to an equivalent total compaction effort. Due to the variety of the mechanically operated rammer devices, e.g. circular or sector faces, and considering that the compaction using the manual rammer is the referee test, it was decided to consider both methods, manual and mechanical compactions, in PTS in order to study the possible influence of thesedifferent rammer operating procedures on the soil compaction characteristics.

The compaction tests were performed by varying the soil water content in six test fractions. Calculating the dry density of the compacted specimens, based on the mold volume and on the soil water content evaluated by the oven drying process, it was possible to plot graphically the dry density on $\mathrm{Y}$-axis and the water content on $\mathrm{X}$-axis and, consequently, to obtain the soil compaction curve. The results interpolated from the compaction curve were the maximum dry density and the optimum water content.

Since 2006 to 2009, annual PTS were organized including the modified Proctor compaction tests and performed according the procedure described above. The main properties of the soils, Soil 1 (2006), Soil 2 (2007), Soil 3 (2008) and Soil 4 (2009), are presented in Table1. The indicated values for each soil are the 
Table 1 Properties of soils.

\begin{tabular}{|c|c|c|c|c|c|c|c|c|}
\hline \multirow{2}{*}{ Property } & & \multicolumn{4}{|c|}{ Laboratory tests } & \multicolumn{3}{|c|}{ Field tests } \\
\hline & & Soil 1 & Soil 2 & Soil 3 & Soil 4 & Site 1 & Site 2 & Site 3 \\
\hline \multirow{9}{*}{$\begin{array}{l}\text { Particle-size analysis } \\
\text { Percentage of } \\
\text { accumulated material } \\
\text { passing in sieve (mm) }\end{array}$} & 19.0 & 100 & 100 & 100 & 100 & 100 & 100 & 100 \\
\hline & 9.50 & 99 & 99 & 100 & 100 & 98 & 98 & 100 \\
\hline & 4.75 & 97 & 96 & 100 & 100 & 96 & 96 & 98 \\
\hline & 2.00 & 82 & 75 & 89 & 89 & 84 & 84 & 89 \\
\hline & 0.850 & 54 & 52 & 65 & 68 & 53 & 53 & 74 \\
\hline & 0.425 & 37 & 38 & 46 & 50 & 29 & 29 & 60 \\
\hline & 0.250 & 27 & 30 & 34 & 39 & 21 & 21 & 45 \\
\hline & 0.106 & 16 & 20 & 19 & 25 & 17 & 17 & 19 \\
\hline & 0.075 & 13 & 17 & 16 & 21 & 16 & 16 & 17 \\
\hline \multicolumn{2}{|l|}{ Liquid Limit (\%) } & NP & NP & NP & NP & 27 & 27 & 22 \\
\hline \multicolumn{2}{|l|}{ Plasticity Index (\%) } & NP & $\mathrm{NP}$ & $\mathrm{NP}$ & NP & 11 & 11 & NP \\
\hline \multicolumn{2}{|l|}{ Particle Density } & 2.63 & 2.64 & 2.65 & 2.65 & $(*)$ & $(*)$ & $(*)$ \\
\hline \multicolumn{2}{|c|}{ Unified Soil Classification System } & SM & SM & SM & SM & SC & SC & SC \\
\hline
\end{tabular}

Notes: (*) Property not determined; NP - Non Plastic Soil.

average of all results obtained by the participants.

The soils have very similar properties, corresponding to the same group, SM, according to the Unified Soil Classification System (Table 1).

\subsection{Field Tests}

In the field tests, wet density and water content were evaluated by following the standard procedures: sand cone method (conventional method) according to the ASTMD1556 [13]; nuclear method according to the ASTMD6938 [14]. In the sand cone tests, the soil water content was obtained by drying for $24 \mathrm{~h}$ the excavated material, at $105-110{ }^{\circ} \mathrm{C}$, in the laboratory pivot. In the case of the nuclear method, the parameters measured were the wet density, measured directly on the soil surface (backscatter mode) and at a test depth of $300 \mathrm{~mm}$ (direct transmission mode), and the water content measured in direct transmission mode. Taking into account the nuclear gauge operation to measure the soil water content, it was also adopted the concept of volumetric water content (water mass per unit volume), in addition to the gravimetric water content used in the laboratory tests (oven dry method).

The PTS of the field tests were performed in three sites: Site 1 (2010), Site 2 (2012) and Site 3 (2013).
Sites 1 and 2 are related to the same location in aselected quarry. It means that a similar soil and in a natural state was tested. In the case of Site 3, we tested a compacted subgrade soil of a road pavement during the construction phase. The main properties and the classification of the soils are presented in Table 1.

In the test sites, a homogeneous and horizontal area was selected in order to perform the field tests. The area was divided in three sections where the test locations were defined as it is represented schematically in Fig. 1.

Taking into account the number of participants, the test locations were distributed randomly by the participants according to the tables in Fig. 1. Different nuclear gauges devices and operators have participated in PTS.

The density and water content were determined first by using the nuclear gauge, previously calibrated as recommended. Measurements were performed in a backscatter mode and, then, in direct transmission. The time selected for readings was fixed at one minute. Three measurements were taken at each location. Interval between readings was two minutes. Thereafter, the sand replacement method has followed exactly at the same location. 


\begin{tabular}{|c|c|c|c|}
\hline Laboratory Section & 1 & 2 & 3 \\
\hline L1 & A & D & E \\
\hline L2 & B & E & D \\
\hline L3 & C & F & C \\
\hline L4 & D & H & B \\
\hline L5 & E & I & A \\
\hline L6 & F & G & I \\
\hline L7 & G & C & H \\
\hline L8 & H & B & G \\
\hline
\end{tabular}

Sites $1 / 2$

\begin{tabular}{|c|c|c|c|}
\hline Laboratory Section & 1 & 2 & 3 \\
\hline L1 & A & B & D \\
\hline L2 & B & A & E \\
\hline L3 & D & B & A \\
\hline L4 & E & D & B \\
\hline \multicolumn{4}{|c|}{ Site 3 }
\end{tabular}

$\stackrel{1 \mathrm{~m}}{\longleftrightarrow} \stackrel{1 \mathrm{~m}}{\longrightarrow}$

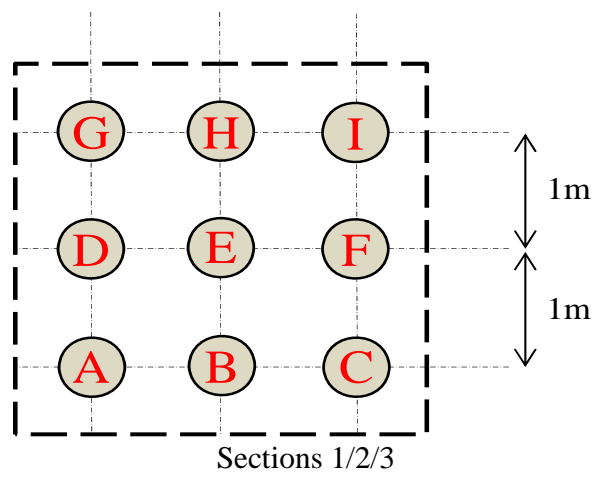

Fig. 1 Location scheme and organization of field tests.

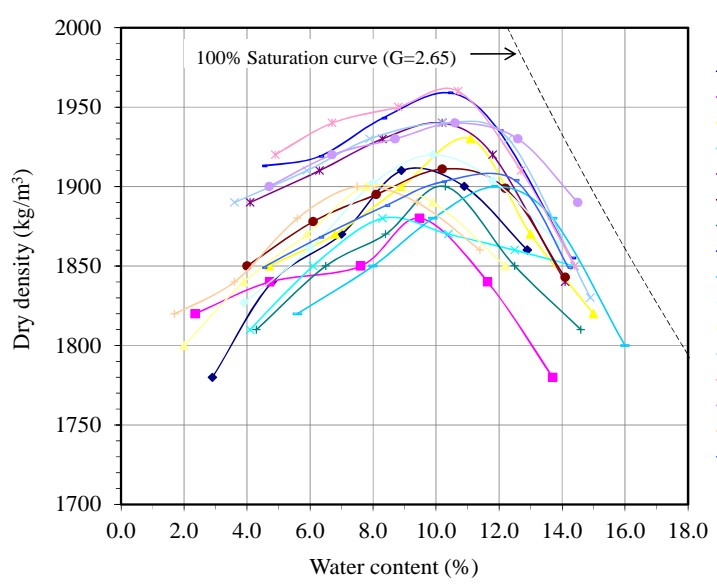

(a)

\section{Results and Discussion}

\subsection{Compaction Tests}

Fig. 2 shows, as an example, the modified Proctor compaction curves obtained by the total participant laboratories for Soil 4 (PTS organized in 2009). The curve for complete saturation is also represented, using the particle density presented in Table 1.

Based on the compaction curve, the values of the optimum water content and the maximum dry density were obtained by the interpolation of the maximum of the compaction curve.

Fig. 3 presents the results for the compaction characteristics, optimum water content and maximum dry density, of all laboratories in the same case of Soil 4, based on the correspondent compaction curves represented in Fig. 2. The procedure demonstrated for Soil 4 (2009) was repeated for all the other soils, concerning PTS organized in 2006 (Soil 1), 2007 (Soil 2) and 2008 (Soil 3).

Fig. 4 shows the comparison of all results between manual and mechanical compactions. Table 2 presents the mean and standard deviation of the compaction parameters. As each laboratory only provided one compaction curve, repeatability and reproducibility analysis was considered without significance. In general, regarding the best-fit line parallel with the line of the equality (Fig. 4), it could be concluded that there

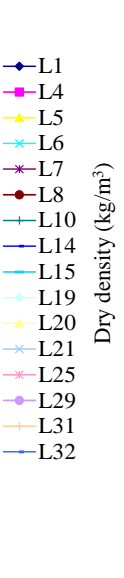

(b)

Fig. 2 Compaction curves for Soil 4: (a) manual compaction and (b) mechanical compaction. 


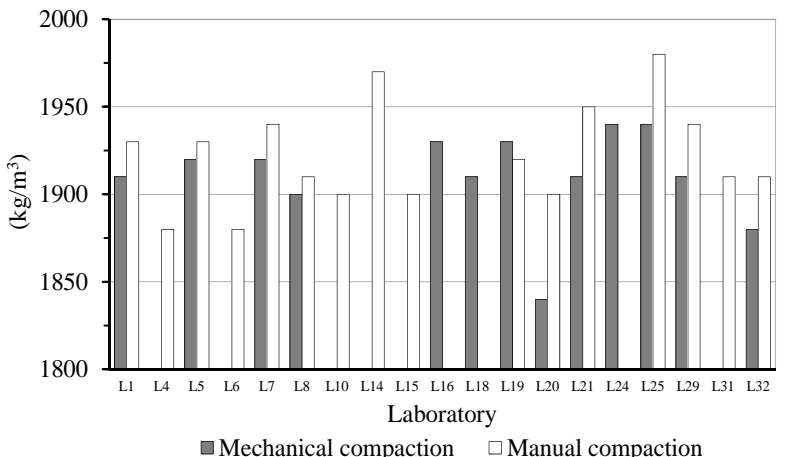

(a)

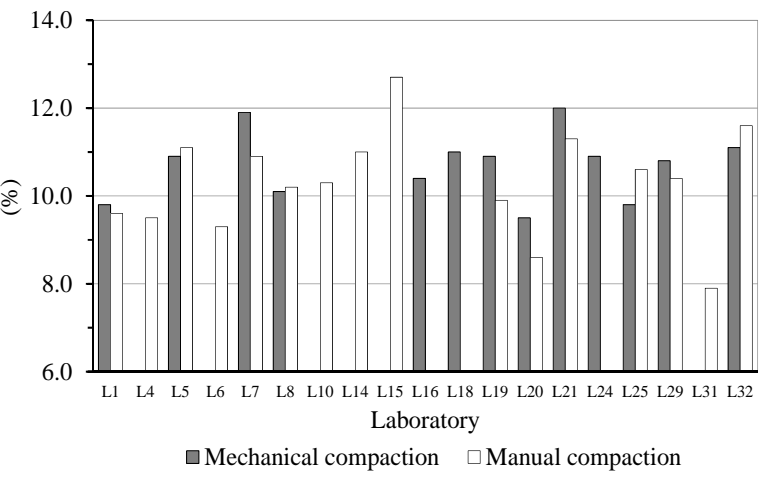

(b)

Fig. 3 Results of laboratories for Soil 4: (a) maximum dry density and (b) optimum water content.

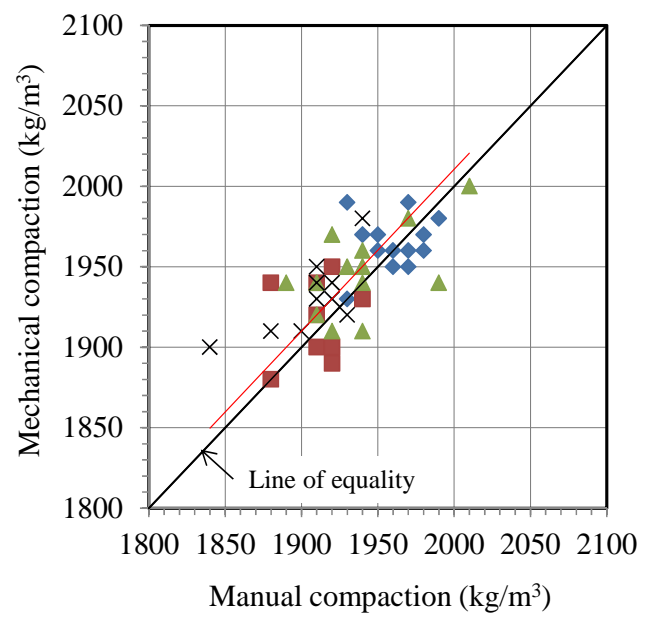

(a)

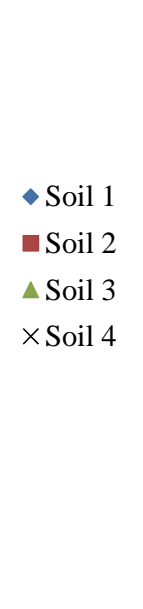

(20)

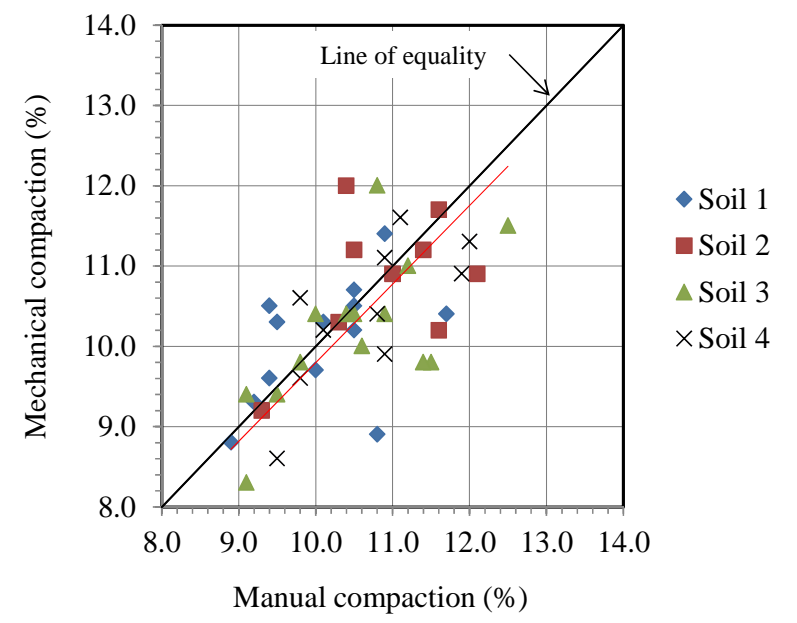

(b)

Fig. 4 Comparison between manual and mechanical compactions: (a) maximum dry density and (b) optimum water content.

Table 2 Results of statistical analysis of laboratory tests.

\begin{tabular}{|c|c|c|c|c|c|c|c|c|}
\hline \multirow{3}{*}{ Soil } & \multicolumn{4}{|c|}{ Maximum dry density $\left(\mathrm{kg} / \mathrm{m}^{3}\right)$} & \multicolumn{4}{|c|}{ Optimum water content (\%) } \\
\hline & \multicolumn{2}{|c|}{ Manual compaction } & \multicolumn{2}{|c|}{ Mechanic compaction } & \multicolumn{2}{|c|}{ Manual compaction } & \multicolumn{2}{|c|}{ Mechanic compaction } \\
\hline & $X$ & $S D$ & $X$ & $S D$ & $X$ & $S D$ & $X$ & $S D$ \\
\hline 1 & 1964 & 15.4 & 1955 & 25.3 & 10.0 & 0.68 & 10.2 & 0.77 \\
\hline 2 & 1913 & 23.8 & 1910 & 17.3 & 10.6 & 0.93 & 10.9 & 0.78 \\
\hline 3 & 1948 & 23.5 & 1939 & 31.0 & 10.2 & 0.85 & 10.5 & 0.93 \\
\hline 4 & 1922 & 28.1 & 1911 & 25.9 & 10.3 & 1.15 & 10.7 & 0.73 \\
\hline
\end{tabular}

is not a clear tendency between the two compaction methods.

Differences of the soil compaction characteristics are negligible taking into account the uncertainty due to the scattering of results.

\subsection{Quality Control Tests}

Table 3 presents the results of the statistical analysis of the field tests performed by the nuclear method. In general, the repeatabilityis in accordance with the values indicated in ASTMD6938 [14]. In terms of reproducibility, values for the density readings are less satisfactory, with exception for the water content (gravimetric and volumetric values). Direct transmission mode in density readings shows a better reproducibility and repeatability than backscatter mode. Similarly, Table 4 presents the results of the statistical analysis of conventional methods and, in comparison to 
Table 3 Results of statistical analysis of field tests, nuclear method.

\begin{tabular}{|c|c|c|c|c|c|c|c|c|c|c|}
\hline \multirow{2}{*}{ Parameter } & \multirow{2}{*}{ Mode } & \multirow{2}{*}{ Site } & \multirow{2}{*}{$X_{X}$} & \multirow{2}{*}{$S D_{X}$} & \multicolumn{3}{|c|}{ Repeatability } & \multicolumn{3}{|c|}{ Reproducibility } \\
\hline & & & & & $\overline{S D_{r}}$ & $C V_{r}(\%)$ & $r$ & $\overline{S D_{R}}$ & $C V_{R}(\%)$ & $R$ \\
\hline \multirow{6}{*}{$\begin{array}{l}\text { Wet density } \\
\left(\mathrm{kg} / \mathrm{m}^{3}\right)\end{array}$} & \multirow{3}{*}{$\begin{array}{l}\text { Direct } \\
\text { transmission }\end{array}$} & 1 & 2,094 & 34.9 & 6.1 & 0.3 & 17 & 34.6 & 1.7 & 98 \\
\hline & & 2 & 2,078 & 47.5 & 8.4 & 0.4 & 24 & 48.1 & 2.3 & 136 \\
\hline & & 3 & 2,142 & 38.7 & 6.3 & 0.3 & 18 & 42.9 & 2.0 & 121 \\
\hline & \multirow{3}{*}{ Backscatter } & 1 & 2,015 & 59.6 & 10.8 & 0.5 & 31 & 60.2 & 3.0 & 170 \\
\hline & & 2 & 1,969 & 89.0 & 14.6 & 0.7 & 41 & 91.5 & 4.6 & 259 \\
\hline & & 3 & 2,197 & 80.3 & 10.0 & 0.5 & 28 & 73.8 & 3.4 & 209 \\
\hline \multirow{3}{*}{ Water content (\%) } & \multirow{3}{*}{$\begin{array}{l}\text { Direct } \\
\text { transmission }\end{array}$} & 1 & 5.1 & 0.51 & 0.20 & 4.8 & 0.7 & 0.60 & 10.9 & 1.6 \\
\hline & & 2 & 4.5 & 1.35 & 0.20 & 4.2 & 0.5 & 1.40 & 30.1 & 3.8 \\
\hline & & 3 & 7.8 & 0.36 & 0.22 & 2.8 & 0.6 & 0.40 & 5.2 & 1.1 \\
\hline \multirow{3}{*}{$\begin{array}{l}\text { Volumetric water } \\
\text { content }\left(\mathrm{kg} / \mathrm{m}^{3}\right)\end{array}$} & \multirow{3}{*}{$\begin{array}{l}\text { Direct } \\
\text { transmission }\end{array}$} & 1 & 102 & 10.4 & 4.6 & 4.5 & 13 & 11.0 & 10.8 & 31 \\
\hline & & 2 & 89 & 25.1 & 3.6 & 4.0 & 10 & 25.3 & 28.4 & 71 \\
\hline & & 3 & 155 & 7.7 & 4.2 & 2.7 & 12 & 8.4 & 5.4 & 24 \\
\hline
\end{tabular}

Table 4 Results of statistical analysis of field tests, conventional method.

\begin{tabular}{|c|c|c|c|c|c|c|c|c|c|}
\hline \multirow{2}{*}{ Parameter } & \multirow{2}{*}{ Procedure } & \multirow{2}{*}{$X_{X}$} & \multirow{2}{*}{$S D_{X}$} & \multicolumn{3}{|c|}{ Repeatability } & \multicolumn{3}{|c|}{ Reproducibility } \\
\hline & & & & $S D_{r}$ & $C V_{r}(\%)$ & $r$ & $S D_{R}$ & $C V_{R}(\%)$ & $R$ \\
\hline Wet density $\left(\mathrm{kg} / \mathrm{m}^{3}\right)$ & Sand-cone replacement & 2072 & 58.2 & 66.6 & 3.2 & 189 & 87.2 & 4.2 & 247 \\
\hline Water content (\%) & Oven dry & 4.8 & 0.48 & 0.57 & 11.8 & 1.6 & 0.68 & 14.1 & 1.9 \\
\hline
\end{tabular}

nuclear method, repeatability and reproducibility are poor.

Fig. 5 shows the difference between direct transmission and the backscatter modes in wet density readings. An improved accuracy is observed for direct transmission mode.

The results from Site 1 were used to compare the test results, wet density and volumetric water content, between conventional and nuclear methods.

Regarding the line of the equality, the results presented in Fig. 6 confirmed an expected difference for both the wet density and the volumetric water content. It means that a correction of nuclear gauge readings is desirable in the field quality control. From the linear regression adjustments of the test results, it could be concluded that the results of the wet density obtained by direct transmission mode are closer to the sand cone values and regression analysis is more acceptable. Although the poor quality of the results adjustment in general, identical conclusion was valid for the volumetric water content, in the case of the direct transmission mode.

Despite all the criteria used in the selection of the tested sites, nevertheless a certain variability of the soil density and water content between sections were found. It means that a certain variability of reproducibility could be responsible by an unreal evaluation of the laboratories performance.

\section{Conclusions and Recommendations}

Based on the PTS performed by different operators and test devices, this paper has presented some studies

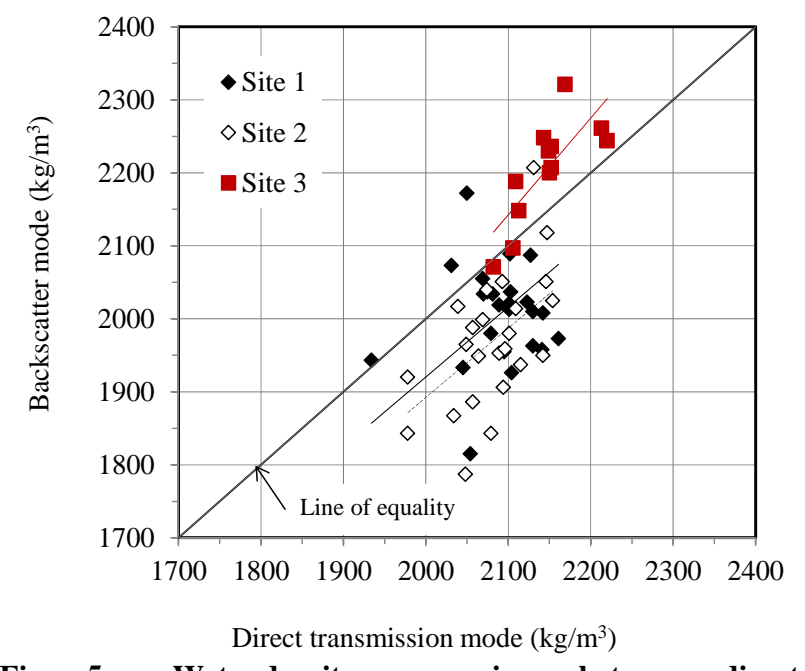

Fig. 5 Wet density comparison between direct transmission and backscatter modes. 


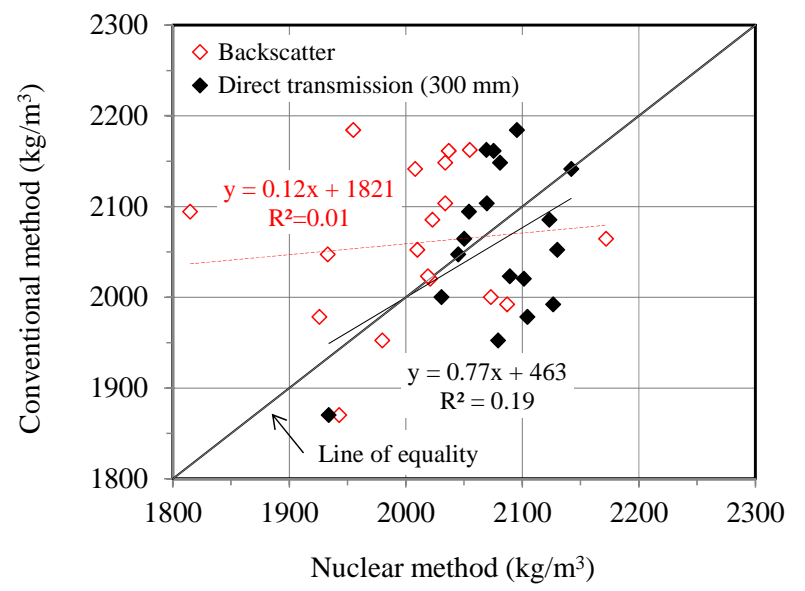

(a)

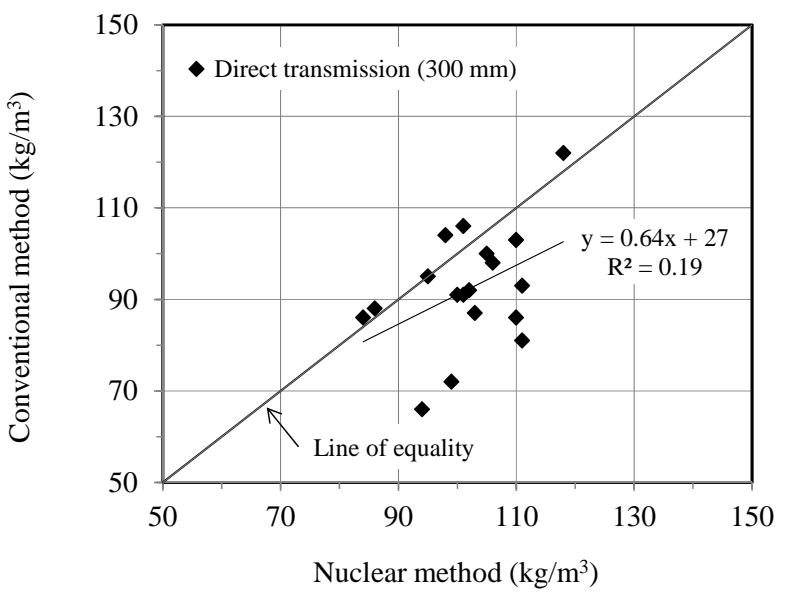

(b)

Fig. 6 Comparison between conventional and nuclear methods: (a) wet density and (b) volumetric water content.

related to soil compaction through the laboratory and field tests with importance in the quality control of embankments construction.

Laboratory Proctor tests have allowed a direct comparison between the use of the manual and mechanical rammer in the soil compaction characteristics. Regarding the results concerning the four soils, there was no clear tendency observed between the two procedures. It could be concluded that the difference of the methods was negligible taking into account the uncertainty due to the scattering of results. For this reason, it is recommended to perform the PTS without specifying the compaction method.

In the case of the field tests and concerning the comparison of conventional and nuclear methods, the results confirmed: (1) the expected difference between these methods; (2) the importance for a correction of the nuclear method results; and (3) the wet density readings obtained by the direct transmission mode of the nuclear gauge were closer to the sand cone test results and the regression analysis was more acceptable.

Regarding exclusively to the nuclear method, it was observed: (1) a difference between the direct transmission and backscatter modes in wet density readings; and (2) animproved accuracy for the case of the direct transmission mode.

The paper has also presented statistical results concerning the repeatability and reproducibility of the test results from nuclear and conventional methods. In general, repeatability and reproducibility was more satisfactory for the nuclear method.

The results achieved in this paper recommend that a more acceptable reproducibility of field tests should be obtained by a better control of the homogeneous conditions of the test sites. In the case of the nuclear method, it was confirmed that the direct transmission method is preferable for the quality control of soil compaction.

It is also recommended the further validation of these conclusions in the context of others PTS performed in different types of soils and covering a larger range of the density and water content values.

\section{References}

[1] Y.K. Cho, K. Kabassi, C. Wang, Framework of non-nuclear methods evaluation for soil QC and QA in highway pavement construction, KICEM Journal of Construction Engineering and Project Management 2-2 (2012) 45-52.

[2] E.S. Berney, J.D. Kyzar, Evaluation of nonnuclear soil moisture and density devices for field quality control, Transportation Research Record: Journal of the Transportation Research Board 2310 (2012) 18-26.

[3] M. Veenstra, D.J. White, V.R. Schaefer, Rapid field testing techniques for determining soil density and water content, in: Mid-Continent Transportation Research Symposium, Ames, Yowa, USA, 2005, pp. 1-13. 
[4] NATA, Technical Note 32, Use of nuclear gauges for testing soils and asphalt, National Association of Testing Authorities, Australia, 2013.

[5] S. Altun, A. Sezer, V. Okur, G. Ozden, Comparison of compaction control parameters obtained by different test methods, in: 12th International Conference of International Association for Computer Methods and Advances in Geomechanics, Goa, India, 2008, pp. 1671-1678.

[6] S. Altun, A.B.G. Oktepe, A. Sezer, Investigation of parameters of compaction testing, Turkish Journal of Engineering and Environmental Sciences 32 (2008) 201-209.

[7] J. Neves, A.M. Duarte, C. Silva, R. Candeias, Contribution of PTS to the laboratory and in situ studies related to soils compaction tests, in: 4nd International Proficiency Testing Conference, Barsov, Romania, 2013, pp. 17-24.

[8] ISO/IEC 17043:2010, Conformity assessment, General requirements for proficiency testing, International Organization for Standardization.

[9] EN ISO/IEC 17025:2005, General requirements for the competence of testing and calibration laboratories, European Committee for Standardization.

[10] ISO 5725-2:1994, Accuracy (trueness and precision) of measurement methods and results. Part 2: Basic method for the determination of repeatability and reproducibility of a standard measurement method, International Organization for Standardization.

[11] ISO 13528:2005, Statistical methods for use in proficiency testing by inter laboratory comparisons, International Organization for Standardization.

[12] ASTM D1557-12, Standard test methods for laboratory compaction characteristics of soil using modified effort $\left(56,000 \mathrm{ft}-\mathrm{lbf} / \mathrm{ft}^{3}\left(2,700 \mathrm{kN}-\mathrm{m} / \mathrm{m}^{3}\right)\right)$, American Society for Testing Materials, 2012.

[13] ASTM D1556-07, Standard test method for density and unit weight of soil in place by the sand-cone method. American Society for Testing Materials, 2007.

[14] ASTM D6938-10, Standard test method for in-place density and water content of soil and soil-aggregate by nuclear methods (shallow depth), American Society for Testing Materials, 2010. 